\title{
Analysis of the time-to-onset of osteonecrosis of jaw with bisphosphonate treatment using the data from a spontaneous reporting system of adverse drug events
}

\author{
Mitsuhiro Nakamura ${ }^{1 *}$, Ryogo Umetsu ${ }^{1,5}$, Junko Abe ${ }^{1,2}$, Toshinobu Matsui $^{1}$, Natsumi Ueda ${ }^{1}$, Yamato Kato ${ }^{1}$,
} Sayaka Sasaoka ${ }^{1}$, Kohei Tahara ${ }^{3}$, Hirofumi Takeuchi ${ }^{3}$ and Yasutomi Kinosada ${ }^{4}$

\begin{abstract}
Background: Bisphosphonates (BPs) are potent antiresorptive agents used to treat osteoporosis and the complications associated with malignant bone metastasis. The aim of this study was to evaluate the incidence of bisphosphonate-related osteonecrosis of the jaw (BRONJ) using the Japanese Adverse Drug Event Report (JADER) database. In particular, we focused on the time-to-onset profile of BRONJ.

Findings: We analyzed reports of BRONJ in the JADER database and calculated the reporting odds ratio (ROR) of BPs potentially associated with BRONJ. We applied the weibull shape parameter to time-to-event data in JADER. The drugs selected for this investigation were seven BPs approved in Japan (alendronate [intraveneous, I.V.], pamidronate, and zoledronate as I.V. BPs; and alendronate (oral), etidronate, minodronate, and risedronate as oral BPs). We analyzed reports of BRONJ events associated with BPs in the JADER database from April 2004 to November 2014. The median value of BRONJ cases caused by alendronate (I.V.), pamidronate, zoledronate, alendronate (oral), etidronate, minodronate, and risedronate were 1342, 812, 486, 863, 1461, 432, and 730 days, respectively. The lower $95 \%$ confidence interval of the Weibull-shape parameter $\beta$ for I.V. BPs (pamidronate and zoledronate) exceeded 1. The risk of BRONJ with I.V. BPs increased over time.

Conclusion: Thus, the incidence of BRONJ with BP treatment should be closely monitored for a 3-year period. Further studies are required to draw conclusions, and we believe that this information about BRONJ induced by BPs will prove beneficial to patients and pharmacists.
\end{abstract}

Keywords: Bisphosphonate, Osteonecrosis of jaw, Japanese adverse drug event report database

\section{Findings}

\section{Background}

Bisphosphonates (BPs) are widely used for the treatment of osteoporosis and complications associated with malignant bone metastasis [1]. Bisphosphonaterelated osteonecrosis of the jaw (BRONJ) has been recognized as an uncommon but severe adverse

\footnotetext{
* Correspondence: mnakamura@gifu-pu.ac.jp

'Laboratory of Drug Informatics, Gifu Pharmaceutical University, 1-25-4 Daigaku-nishi, Gifu 501-1196, Japan

Full list of author information is available at the end of the article
}

event that affects the quality of life of patients. The risk of BRONJ depends on the type of BPs and the duration of exposure, and the majority of BRONJ patients experience the complication following simple dentoalveolar surgery $[2,3]$. According to the position paper on BRONJ from American Association of Oral and Maxillofacial Surgeons (AAOMS), patients receiving oral BPs are at a risk of BRONJ, but to a much lesser degree than those treated with I.V. BPs. The risk of oral BPs may be associated with longer treatment durations, such as over $3-4$ years $[2,3]$.

\section{Biomed Central}


Since BRONJ is a rare adverse event [4], epidemiologic research on this condition is difficult. The regulatory authority in Japan, the Pharmaceuticals and Medical Devices Agency (PMDA), has released the spontaneous reporting system (SRS) of the Japanese Adverse Drug Event Report (JADER) database. The JADER database is the largest and best-known database, and it reflects the realities of clinical practice. Therefore, JADER has been recognized as one of the primary tools for pharmacovigilance assessments [5]. Analysis of time-to-onset data has been proposed as a method to detect signals for adverse drug reactions (ADRs) in SRS [6-8]. As far as we know, analyses of the time-to-onset for BRONJ using the JADER database are rare. The aim of this study was to assess the time-to-onset data of BRONJ by BP treatment.

\section{Methods}

Adverse events recorded from April 2004 to November 2014 in the JADER database were downloaded from the PMDA website (http://www.pmda.go.jp). The database consists of 4 data tables: patient demographic information (demo), drug information (drug), adverse events (reac), and primary disease (hist). The adverse events in "reac" are coded according to the terminology preferred by the Medical Dictionary for Regulatory Activities (MedDRA) [9]. "Drug" file (drug information) includes role codes assigned to each drug: suspected drug (higiyaku in Japanese), interacting drug (sougosayou in Japanese), and concomitant drug (heiyouyaku in Japanese). Suspected drugs were extracted and analyzed in this study. The drugs selected for this investigation were seven BPs approved in Japan (alendronate [intraveneous, I.V.], pamidronate, and zoledronate as I.V. BPs; alendronate (oral), etidronate, minodronate, and risedronate as oral BPs). BPs were grouped by dosages and each BP was stratified by dosages: pamidoronate (30-
$45 \mathrm{mg}$ ), pamidoronate (90 mg), zoledronate ( $4 \mathrm{mg})$, alendronate $(5 \mathrm{mg})$, alendronate $(35 \mathrm{mg})$, risedronate $(2.5 \mathrm{mg})$, and risedronate $(17.5 \mathrm{mg})$. We used the preferred term "osteonecrosis of jaw" to match cases of BRONJ according to MedDRA. To detect the incidence of BRONJ, we calculated the reporting odds ratio (ROR), which is an established parameter for pharmacovigilance research, using a disproportionality analysis [10]. "Cases" were defined as patients who reported BRONJ, while "non-cases" consisted of patients associated with all other reports. The ROR is the ratio of the odds of reporting adverse events versus all other events associated with BPs compared to the reporting odds for all other drugs present in the database. To compare the "cases" and "non-cases," we calculated the RORs as (a:c)/(b:d) (Fig. 1). RORs were expressed as point estimates with a $95 \%$ confidence interval (CI). For signal detection, general qualitative judgments were used. The detection of a signal was dependent on the signal indices exceeding a predefined threshold. ROR values $<1$ indicated no exposure-event association, and estimates $>1$ indicated exposure-event safety signals. Safety signals are considered significant when the ROR estimates and the lower limits of the corresponding $95 \%$ CI are $>1$ [10].

The median of the data, quartiles, and the Weibull shape parameter (WSP) were utilized in evaluations of the time-to-onset data for BRONJ. Time-to-onset from the JADER database was calculated from the beginning of the time of a subject's first prescription to the occurrence of the adverse events. Different BPs were not administered at the same time. For duplicate entries of the same BPs in the same case, we adopted the most recent BP entry in order to identify the beginning of the time of a subject's first prescription. The WSP test is used for statistical analysis of time-to-onset data and can describe the non-constant rate of incidence of ADRs (i.e., the risk of increase or decrease over time) $[7,8]$.

\begin{tabular}{lccc}
\hline & $\begin{array}{c}\text { Adverse event of } \\
\text { interest }\end{array}$ & $\begin{array}{l}\text { Other adverse } \\
\text { event of interest }\end{array}$ & Total \\
\hline Drug of interest & $\mathrm{a}$ & $\mathrm{b}$ & $\mathrm{a}+\mathrm{b}$ \\
Other drugs of interest & $\mathrm{c}$ & $\mathrm{d}$ & $\mathrm{c}+\mathrm{d}$ \\
\hline Total & $\mathrm{a}+\mathrm{c}$ & $\mathrm{b}+\mathrm{d}$ & $\mathrm{a}+\mathrm{b}+\mathrm{c}+\mathrm{d}$ \\
\hline $\mathrm{ROR}=\frac{\mathrm{a} / \mathrm{c}}{\mathrm{b} / \mathrm{d}}=\frac{\mathrm{a} \mathrm{d}}{\mathrm{b} \mathrm{c}}$ & & & \\
$95 \% \mathrm{Cl}=\mathrm{e} \frac{\ln (\mathrm{ROR}) \pm}{1.96} \sqrt{\frac{1}{\mathrm{a}}+\frac{1}{\mathrm{~b}}+\frac{1}{\mathrm{c}}+\frac{1}{\mathrm{~d}}}$ & &
\end{tabular}

Fig. 1 Two by two table used for the calculation of reporting odds ratios 
The shape parameter $\beta$ of the Weibull distribution indicated that the hazard without a reference population; when $\beta$ is equal to 1 , the hazard is estimated to be constant over time. If $\beta$ is greater than 1 and the $95 \%$ CI of $\beta$ excluded the value 1 , the hazard was considered to increase over time.

All data analyses were performed by JMP 11.0 (SAS Institute Inc., Cary, NC, USA).

\section{Results}

The JADER database contains 338,224 reports from April 2004 to November 2014. The database contains $4,128,716$ combinations of drugs and ADRs. After extracting the combinations completed within the beginning date of the treatment and the occurrence date of adverse events, a total of $1,777,925$ combinations were analyzed. The number of reports with "osteonecrosis of jaw" was 3,027. The RORs (95 \% CI) of alendronate (I.V.), pamidronate, zoledronate, alendronate (oral), etidronate, minodronate, and risedronate were 43.7 (22.1-86.4), 315.0 (256.3-387.0), 346.2 (308.2-388.8), 92.3 (81.4-104.5), 160.3 (83.5-307.7), 17.3 (12.7-23.5), and 48.4 (40.3-58.0), respectively (Table 1 ). The number of cases for zoledronate in males and females were 301 and 474, respectively (Table 1). The number of cases for alendronate (oral) in males and females were 22 and 379, respectively.
The RORs stratified by dosages are summarized in Table 2. The complete report with dosage amount was analyzed. The RORs for pamidoronate (30-45 mg), pamidoronate $(90 \mathrm{mg})$, zoledronate $(4 \mathrm{mg})$, alendronate $(5 \mathrm{mg})$, alendronate $(35 \mathrm{mg})$, risedronate $(2.5 \mathrm{mg})$, and risedronate $(17.5 \mathrm{mg})$ were 159.4 (107.5-236.2), 298.0 (204.8-433.6), 226.6 (198.8-258.3), 91.7 (75.6-111.3), 68.2 (57.8-80.4), 42.5 (32.9-54.8), and 34.9 (24.3-50.1), respectively.

The number of case reports for alendronate (I.V.), pamidronate, zoledronate, alendronate (oral), etidronate, minodronate, and risedronate was $6,118,408,196,9$, 32 , and 65 , respectively (Table 3 ). The median values for BRONJ caused by alendronate (I.V.), pamidronate, zoledronate, alendronate (oral), etidronate, minodronate, and risedronate were $1342,812,486,863,1461,432$, and 730 days, respectively (Table 3 ). The Weibull distribution parameters for each BP are summarized in Table 3. The lower $95 \%$ CI of $\beta$ for both I.V. BPs (pamidronate and zoledronate) and alendronate (oral) exceeded 1 , but those for other BPs did not exceed 1 (Table 3). The median values for BRONJ caused by pamidronate (30-45 mg), pamidoronate $(90 \mathrm{mg})$, zoledronate $(4 \mathrm{mg})$, alendronate (5 $\mathrm{mg})$, alendronate $(35 \mathrm{mg})$, risedronate $(2.5 \mathrm{mg})$, and risedronate $(17.5 \mathrm{mg})$ were $844,783,488,1263,680,1081$, and 112 days, respectively (Table 4). The lower $95 \%$ CI of

Table 1 Number of reports and reporting odds ratio of BRONJ stratified by gender

\begin{tabular}{|c|c|c|c|c|c|c|c|}
\hline Dosage form & Drug name & & Case & Non-case & Total & Reporting odds ratio & $(95 \% \mathrm{Cl})$ \\
\hline \multirow[t]{9}{*}{ Intravenous } & Alendronate (I.V.) & & 10 & 48 & 58 & 43.7 & $(22.1-86.4)$ \\
\hline & & Male & 2 & 8 & 10 & 52.1 & $(11.1-245.7)$ \\
\hline & & Famale & 8 & 40 & 48 & 41.9 & $(19.6-89.6)$ \\
\hline & Pamidronate & & 223 & 171 & 394 & 315.0 & $(256.3-387.0)$ \\
\hline & & Male & 30 & 35 & 65 & 181.9 & $(111.4-297.0)$ \\
\hline & & Famale & 186 & 128 & 314 & 341.9 & $(271.4-430.8)$ \\
\hline & Zoledronate & & 809 & 972 & 1,781 & 346.2 & $(308.2-388.8)$ \\
\hline & & Male & 301 & 436 & 737 & 176.5 & $(150.9-206.4)$ \\
\hline & & Famale & 474 & 514 & 988 & 271.4 & $(236.5-311.4)$ \\
\hline \multirow[t]{12}{*}{ Oral } & Alendronate (oral) & & 414 & 1,252 & 1,666 & 92.3 & $(81.4-104.5)$ \\
\hline & & Male & 22 & 146 & 168 & 31.8 & $(20.3-49.9)$ \\
\hline & & Famale & 379 & 1,096 & 1,475 & 93.8 & $(82.4-106.8)$ \\
\hline & Etidronate & & 16 & 21 & 37 & 160.3 & $(83.5-307.7)$ \\
\hline & & Male & 3 & 4 & 7 & 156.5 & $(35.0-699.9)$ \\
\hline & & Famale & 13 & 17 & 30 & 160.6 & $(77.9-331.1)$ \\
\hline & Minodronate & & 45 & 558 & 603 & 17.3 & $(12.7-23.5)$ \\
\hline & & Male & 4 & 49 & 53 & 17.0 & $(6.1-47.3)$ \\
\hline & & Famale & 41 & 483 & 524 & 18.1 & $(13.1-25.0)$ \\
\hline & Risedronate & & 152 & 721 & 873 & 48.4 & $(40.3-58.0)$ \\
\hline & & Male & 18 & 81 & 99 & 46.8 & $(28.0-78.2)$ \\
\hline & & Famale & 131 & 614 & 745 & 48.3 & $(39.7-58.7)$ \\
\hline
\end{tabular}


Table 2 Number of reports and reporting odds ratio of BRONJ stratified by formulations and dosages

\begin{tabular}{|c|c|c|c|c|c|c|c|}
\hline Dosage form & Drug name & & Case & Non-case & Total & Reporting odds ratio & $(95 \% \mathrm{Cl})$ \\
\hline \multirow[t]{5}{*}{ Intravenous } & Pamidronate & & 223 & 171 & 394 & 315.0 & $\overline{(256.3-387.0)}$ \\
\hline & & $30 \mathrm{mg}-45 \mathrm{mg}^{\mathrm{a}}$ & 44 & 59 & 103 & 159.4 & $(107.5-236.2)$ \\
\hline & & $90 \mathrm{mg}^{\mathrm{a}}$ & 66 & 48 & 114 & 298.0 & $(204.8-433.6)$ \\
\hline & Zoledronate & & 809 & 972 & 1,781 & 346.2 & $(308.2-388.8)$ \\
\hline & & $4 \mathrm{mg}^{\mathrm{a}}$ & 494 & 651 & 1,145 & 226.6 & $(198.8-258.3)$ \\
\hline \multirow[t]{6}{*}{ Oral } & Arendronate (oral) & & 414 & 1,252 & 1,666 & 92.3 & $(81.4-104.5)$ \\
\hline & & $5 \mathrm{mg}^{\mathrm{a}}$ & 155 & 388 & 543 & 91.7 & $(75.6-111.3)$ \\
\hline & & $35 \mathrm{mg}^{\mathrm{a}}$ & 202 & 702 & 904 & 68.2 & $(57.8-80.4)$ \\
\hline & Risedronate & & 152 & 721 & 873 & 48.4 & $(40.3-58.0)$ \\
\hline & & $2.5 \mathrm{mg}^{\mathrm{a}}$ & 73 & 374 & 447 & 42.5 & $(32.9-54.8)$ \\
\hline & & $17.5 \mathrm{mg}^{\mathrm{a}}$ & 35 & 213 & 248 & 34.9 & $(24.3-50.1)$ \\
\hline
\end{tabular}

${ }^{\mathrm{a}}$ Reports completed with dosage amount were analyzed

$\beta$ for pamidronate (30-45 $\mathrm{mg})$, pamidoronate (90 $\mathrm{mg}$ ), zoledronate $(4 \mathrm{mg})$, alendronate $(5 \mathrm{mg})$, and risedronate (2.5 mg) exceeded 1 , but those for alendronate $(35 \mathrm{mg})$ and risedronate $(17.5 \mathrm{mg})$ did not exceed 1 (Table 4 ).

Figures 2 and 3 show the histogram of the number of cases of BRONJ between 0 day to 4,000 days. The interval of the quartile points was very large in all BPs, but the lower quartile point was over 150 days for all BPs except risedronate $(17.5 \mathrm{mg})$.

\section{Discussion}

The risks of BRONJ related to antiresorptive therapy are well recognized by clinicians [11]. In patients receiving drugs via the I.V. route, the prevalence of BRONJ was $1-10 \%$, while the prevalence was $0.00007-0.04 \%$ in those using the oral route [3]. The I.V. route of administration results in a greater drug exposure than the oral route [2, 3]. Zoledronate is more potent than pamidronate, while pamidronate is more potent than oral BPs [2, 3]. In in vitro analysis, zoledronate was the most potent inhibitor of farnesyl pyrophosphate synthase, followed by risedronate, alendronate, and pamidronate [12]. The inhibition of farnesyl pyrophosphate is associated with effectiveness in suppressing bone turnover in vivo [13]. Several reports have suggested that the pathogenesis of BRONJ is partially associated with osteonecrosis by suppression of bone turnover. In our study, the number of reported cases of BRONJ increased after administration of BPs. The obtained RORs for all of the BPs and their lower limits of $95 \%$ CI were $>1$. The RORs for zoledronate and pamidronate were higher than those for the oral BPs, and the ROR for zoledronate was higher than that for alendronate (I.V.). The results obtained in this study were reasonable in the context of those reported in the literature from the JADER database.
The risk of developing BRONJ associated with oral BPs increases when the duration of therapy exceeds 3-4 years $[2,3]$. The median duration of BP exposure for patients with BRONJ and BRONJ-like features was 4.4 years $[14,15]$. Yoneda et al. demonstrated that the incidence of BRONJ begins to increase 1 year after intravenous $\mathrm{BP}$ and 2-3 years after oral BP administration [11]. In Japan, the mean duration of administration until onset of BRONJ was 23.6 months (2.0 years) for I.V. BPs and 33.3 months (2.8 years) for oral BPs [16]. The median time-to-onset of BRONJ for BPs, zoledronate, pamidronate, and alendronate (oral) was 486 (1.3 years), 812 (2.2 years), and 863 days (2.4 years), respectively. BRONJ with BPs treatment should be closely monitored within 3 years. The results of the shape parameter of the Weibull distribution indicated that the risk of BRONJ with the oral BPs, minodronate and risedronate, is almost constant. The number of case reports for analysis of etidronate, minodronate, and risedronate were less than 100 (Table 3). Owing to the low frequency of disease, studies with small samples need to be interpreted cautiously. However, the risk of BRONJ with I.V. BPs, pamidronate and zoledronate, increased over time. This is likely because of the strong exposure to I.V. BPs among the patients. More than half of the reports on BRONJ with I.V. BP treatment were recorded within 3 years (Figs. 2 and 3). Our results indicate the importance of comparing drug safety profiles using post-marketing real-world data.

Gender was reported as a demographic and systematic risk factor for BRONJ [17]. BRONJ is rare in male patients with osteoporosis [18]. For oral BPs, the number of reports of BRONJ in males was lower than that in females (Table 1). Since zoledronate was used to prevent skeletal fractures in patients with multiple myeloma and prostate cancer, the number of reports for zoledronate in males might be similar to that in females (Table 1). Cumulative $\mathrm{BP}$ exposure has been proposed as an important risk 
Table 3 Time-to-onset analysis of bisphosphonates

\begin{tabular}{|c|c|c|c|c|c|c|c|c|c|}
\hline \multirow[t]{2}{*}{ Dosage form } & \multirow[t]{2}{*}{ Drug name } & \multirow{2}{*}{$\begin{array}{l}\text { Case (number } \\
\text { for analysis) }\end{array}$} & \multirow{2}{*}{$\begin{array}{l}\text { Median of } \\
\text { time-to-onset (day) }\end{array}$} & \multirow{2}{*}{$\begin{array}{l}\text { Lower quartile } \\
\text { of time-to-onset (day) }\end{array}$} & \multirow{2}{*}{$\begin{array}{l}\text { Upper quartile } \\
\text { of time-to-onset (day) }\end{array}$} & \multicolumn{2}{|c|}{ Scale parameter: a } & \multicolumn{2}{|c|}{ Shape parameter: $\beta$} \\
\hline & & & & & & a & $(95 \% \mathrm{Cl})$ & $\beta$ & $(95 \% \mathrm{Cl})$ \\
\hline \multirow[t]{3}{*}{ Intravenous } & Alendronate (I.V.) & $10(6)$ & 1,342 & 691 & 1,701 & 1267.6 & $(737.0-2125.0)$ & 2.15 & $(0.96-3.83)$ \\
\hline & Pamidronate & $223(118)$ & 812 & 567 & 1,227 & 934.7 & $(816.9-1066.3)$ & 1.45 & $(1.26-1.64)$ \\
\hline & Zoledronate & 809 (408) & 486 & 274 & 821 & 631.5 & $(586.8-678.9)$ & 1.41 & $(1.30-1.52)$ \\
\hline \multirow[t]{4}{*}{ Oral } & Alendronate (oral) & 414 (196) & 863 & 432 & 1,463 & 1095.4 & $(970.2-1233.8)$ & 1.23 & $(1.09-1.37)$ \\
\hline & Etidronate & $16(9)$ & 1,461 & 389 & 2,068 & 1390.3 & $(766.8-2442.7)$ & 1.49 & $(0.74-2.63)$ \\
\hline & Minodronate & $45(32)$ & 432 & 196 & 742 & 629.5 & $(408.3-954.8)$ & 0.90 & $(0.69-1.13)$ \\
\hline & Risedronate & $152(65)$ & 730 & 215 & 1,494 & 951.7 & $(730.3-1228.7)$ & 1.02 & $(0.82-1.24)$ \\
\hline
\end{tabular}


Table 4 Time-to-onset analysis of bisphosphonates stratified by formulations and dosages

\begin{tabular}{|c|c|c|c|c|c|c|c|c|c|c|}
\hline \multirow{3}{*}{$\begin{array}{l}\text { Dosage form } \\
\text { Intravenous }\end{array}$} & \multirow{3}{*}{$\begin{array}{l}\text { Drug name } \\
\text { Pamidronate }(30-45 \mathrm{mg})\end{array}$} & \multirow{2}{*}{\multicolumn{2}{|c|}{$\begin{array}{l}\text { Case (number } \\
\text { for analysis) }\end{array}$}} & \multirow{3}{*}{$\begin{array}{l}\begin{array}{l}\text { Median of } \\
\text { time-to-onset (day) }\end{array} \\
844\end{array}$} & \multirow{3}{*}{$\begin{array}{l}\begin{array}{l}\text { Lower quartile } \\
\text { of time-to-onset (day) }\end{array} \\
658\end{array}$} & \multirow{3}{*}{$\begin{array}{l}\begin{array}{l}\text { Upper quartile of } \\
\text { time-to-onset (day) }\end{array} \\
1,199\end{array}$} & \multicolumn{2}{|c|}{ Scale parameter: a } & \multicolumn{2}{|c|}{ Shape parameter: $\beta$} \\
\hline & & & & & & & \multirow{2}{*}{$\begin{array}{l}a \\
775.6\end{array}$} & \multirow{2}{*}{$\frac{(95 \% \mathrm{Cl})}{(641.8-928.9)}$} & \multirow{2}{*}{$\begin{array}{l}\beta \\
1.98\end{array}$} & \multirow{2}{*}{$\frac{(95 \% \mathrm{Cl})}{(1.49-2.53)}$} \\
\hline & & 44 & (35) & & & & & & & \\
\hline & Pamidronate (90 mg) & 66 & (48) & 783 & 532 & 1,041 & 889.5 & $(706.1-1112.6)$ & 1.35 & $(1.09-1.63)$ \\
\hline & Zoredronate (4 mg) & 494 & (355) & 488 & 290 & 811 & 634.1 & $(587.7-683.4)$ & 1.46 & $(1.34-1.59)$ \\
\hline \multirow[t]{4}{*}{ Oral } & Arendronate (5 mg) & 155 & (72) & 1,263 & 757 & 1,951 & 1450.5 & $(1258.1-1664.5)$ & 1.77 & $(1.46-2.12)$ \\
\hline & Arendronate (35 mg) & 202 & $(102)$ & 680 & 309 & 1,106 & 804.9 & $(663.0-972.3)$ & 1.08 & $(0.91-1.25)$ \\
\hline & Risedronate (2.5 mg) & 73 & (39) & 1,081 & 495 & 1,706 & 1288.6 & $(1008.4-1634.3)$ & 1.41 & $(1.06-1.82)$ \\
\hline & Risedronate (17.5 mg) & 35 & (14) & 112 & 33 & 407 & 295.0 & $(129.5-636.9)$ & 0.82 & $(0.96-1.23)$ \\
\hline
\end{tabular}




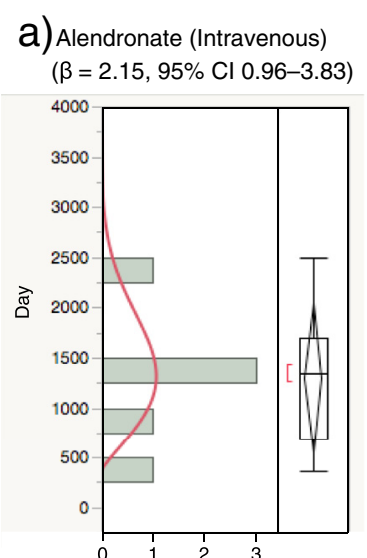

d) Alendronate (Oral)

$(\beta=1.23,95 \% \mathrm{Cl} 1.09-1.37)$

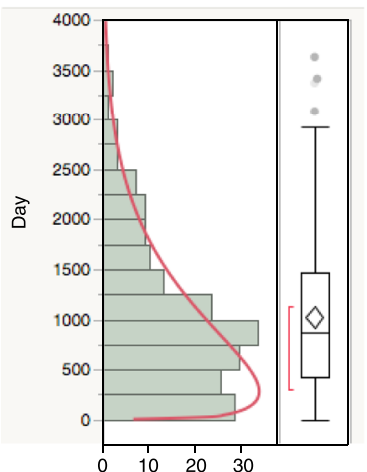

b) Pamidronate

$(\beta=1.45,95 \%$ Cl $1.26-1.64)$

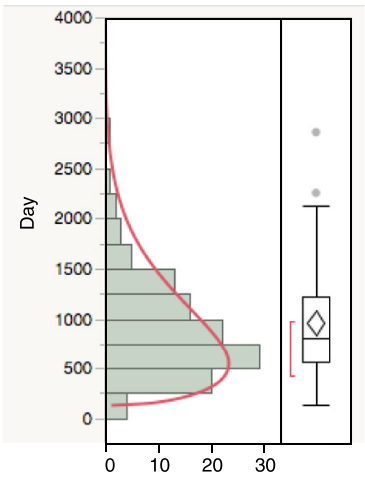

e) Etidronate

( $\beta=1.49,95 \%$ Cl 0.74-2.63)

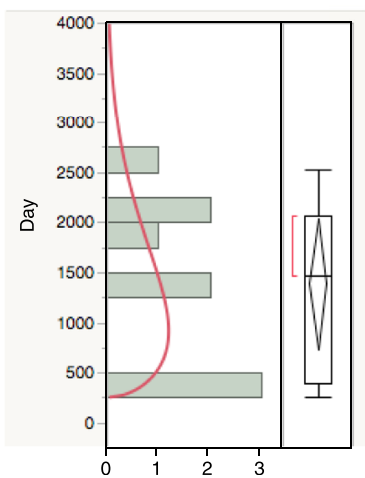

C) Zoledronate

( $\beta=1.41,95 \%$ Cl 1.30-1.52)

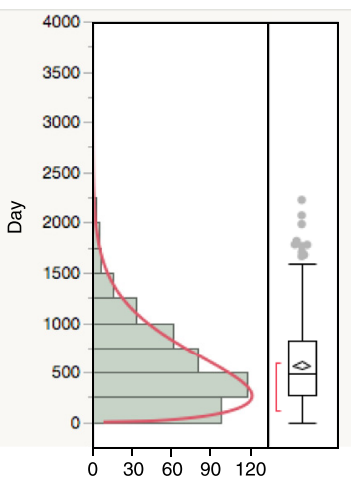

f) Minodronate

( $\beta=0.90,95 \% \mathrm{Cl} 0.69-1.13)$

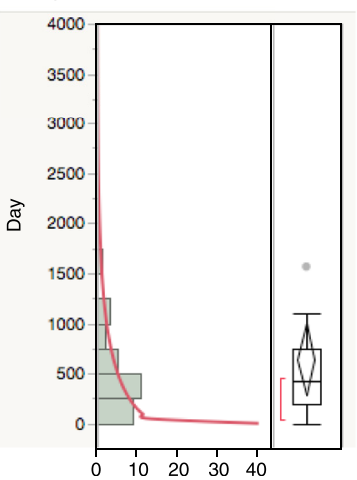

9) Risedronate

( $\beta=1.02,95 \% \mathrm{Cl} 0.82-1.24)$

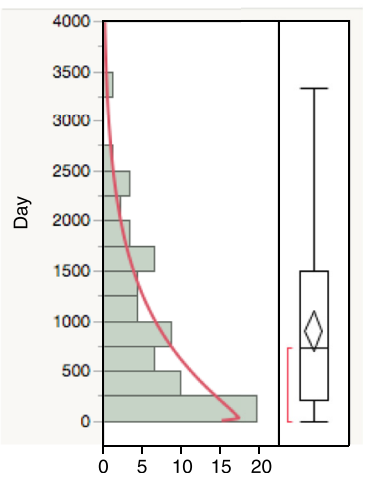

Fig. 2 Histogram and Weibull shape parameter of BRONJ for (a) alendronate (Intravenous), (b) pamidronate, (c) zoledronate, (d) alendronate (oral), (e) etidronate, (f) minodronate and (g) risedronate

factor for the development of BRONJ. There are various BP formulations and dosages. BPs were initially administered orally either once daily (alendronate [ $5 \mathrm{mg}$ ], risedronate [2.5 mg]), once weekly (alendronate [35 mg] and risedronate [17.5 mg]), and, recently, intravenous formulations (zoledronate [4 mg], pamidoronate [30-45 mg], and pamidoronate [90 mg]) has been developed. The median values for BRONJ caused by alendronate (35 mg, 680 days) were almost half that for alendronate ( $5 \mathrm{mg}, 1263$ days) (Table 4). We believe that the findings of this study will be of great value to clinicians who administer BPs to patients.

Several observational studies have identified potential risk factors associated with the development of BRONJ. Age, gender, cancer diagnosis with or without osteoporosis, renal dialysis, obesity, and co-administrated drug were reported as demographic and systematic risk factors for BRONJ [17]. Dentoalveolar surgeries such as extraction and dental implant placement are local risk factors [2, 3]. Corticosteroid use is associated with an increased risk for BRONJ [3]. These covariates should be confirmed by using further epidemiological studies, such as case-control or cohort studies.
SRS, such as the JADER database, is subject to various biases, including over-reporting, under-reporting, missing data, the exclusion of healthy individuals, the lack of denominator, and confounding factors $[5,10,19,20]$. In the JADER database, some of the numbers of reports may reflect duplicate reporting due to factors such as follow-up reports received on a case or different persons reporting on the same patient case. It is recommended that identify duplicate reports of the same patient that come from different reporting sources and excluded these from the analysis. However, there is no key code for the identification of duplicate reports in the JADER database. Further studies are necessary to determine more precisely. Because of these limitations, disproportionality measures (ROR) do not allow for risk quantification. Rather, RORs offer a rough indication of signal strength and are only relevant to the hypothesis. In absolute terms, the ROR indicates an increased risk of adverse event reporting, and not a risk of adverse event occurrence. Therefore, careful attention must be paid to the interpretation of the results from the JADER database. 


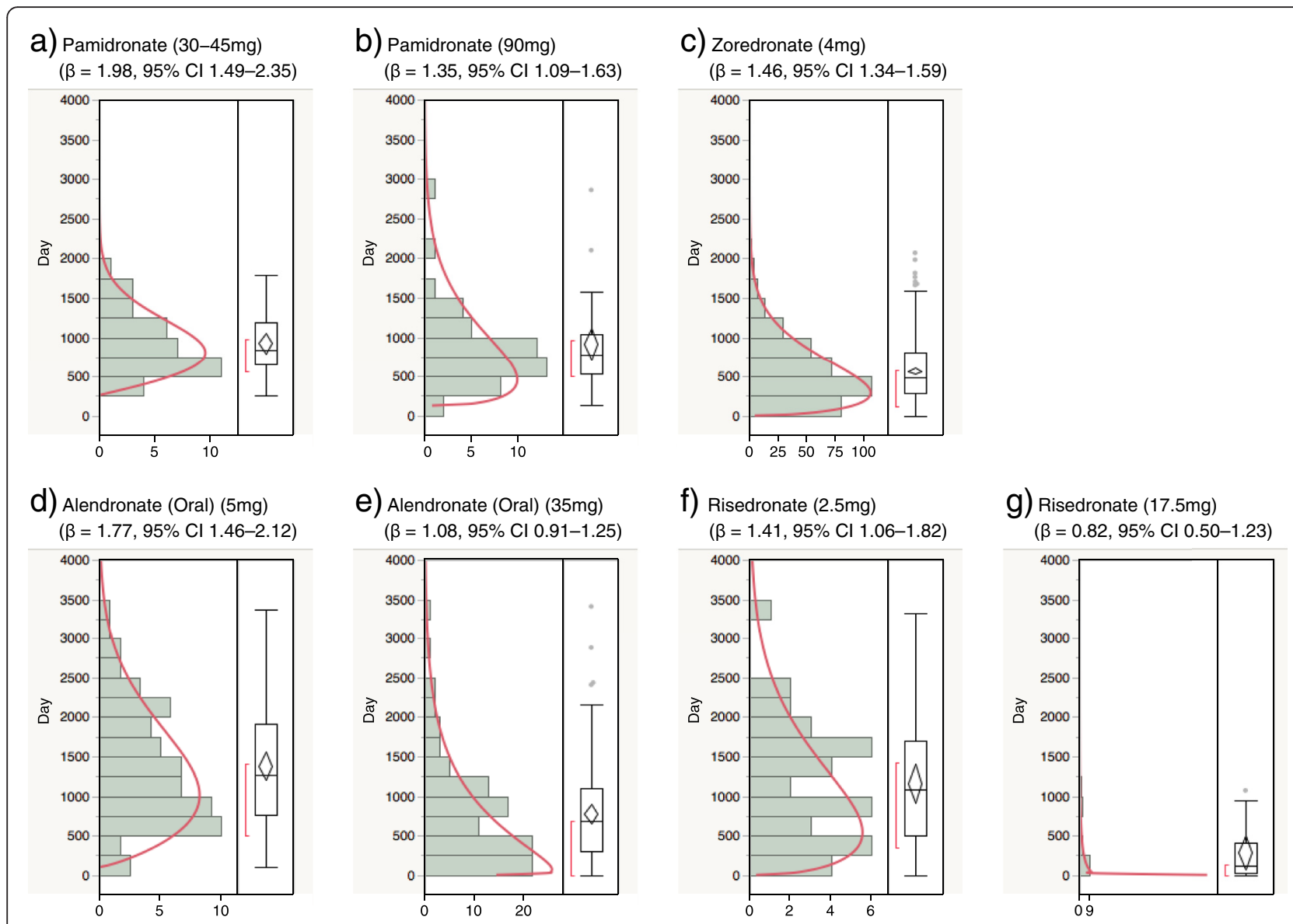

Fig. 3 Histogram and Weibull shape parameter of BRONJ stratified by formulations and dosages for (a) pamidronate (30-45mg), (b) pamidronate (90mg), (c) zoredronate $(4 \mathrm{mg})$, (d) alendronate (oral) $(5 \mathrm{mg})$, (e) alendronate (oral) (35mg), (f) risedronate (2.5mg) and (g) risedronate (17.5mg)

Despite the limitations inherent to SRS, our study indicated that BRONJ with BP treatment typically occurred within 3 years from the start of the treatment with BPs. Despite the clinical correlation between BPs and BRONJ, a definitive causal relationship has yet to be established [3]. There is no way to predict which individuals taking BPs are at greatest risk of developing BRONJ, nor is there evidence of prognostic indicators that are predictive of outcomes. Therefore, clinicians should comply with guidelines and monitor patients for adverse BRONJ events. This study was the first to evaluate the relationship between $\mathrm{BP}$ and BRONJ by using the JADER database. We hope that these data will update the information available to clinicians and be potentially useful for improving the management of BRONJ.

\section{Conclusion}

This study was the first to evaluate the relationship between BPs and BRONJ by using the JADER database. The present analysis demonstrate that the incidence of BRONJ with BP treatment should be closely monitored for a 3-year period. WSP was deemed to be a useful tool for the time-to-onset analysis. We hope that these data will update the information available to clinicians and be potentially useful for improving the management of BRONJ induced by BPs.

\section{Abbreviations}

IV: Intraveneous; BPs: Bisphosphonates; BRONJ: Bisphosphonate-Related Osteonecrosis of Jaw; AAOMS: American Association of Oral and Maxillofacial Surgeons; PMDA: the Pharmaceuticals and Medical Devices Agency; SRS: the Spontaneous Reporting System; JADER: the Japanese Adverse Drug Event Report; ADR: Adverse drug reaction; MedDRA: the Medical Dictionary for Regulatory Activities; ROR: Reporting Odds Ratio; Cl: Confidence Intervals; WSP: Weibull Shape Parameter.

\section{Competing interests}

JA is an employee of Medical Database. The rest of the authors have no conflict of interest.

\section{Authors' contributions}

MN conceived of the study, and participated in its design and coordination and drafted the manuscript. RU conceived of the study and conducted the statistical analysis and drafted the manuscript. JA conceived of the study and participated in its design and drafted the manuscript. TM performed the statistical analysis. NU performed the statistical analysis. YK performed the statistical analysis. SS performed the statistical analysis. KT helped to interpretation of data. HT helped to interpretation of data. YK participated in its design of the study. All authors read and approved the final manuscript. 


\section{Acknowledgement}

This research was partially supported by JSPS KAKENHI Great Number, 24390126.

\section{Author details}

'Laboratory of Drug Informatics, Gifu Pharmaceutical University, 1-25-4 Daigaku-nishi, Gifu 501-1196, Japan. ${ }^{2}$ Medical Database Co., LTD, 3-11-10 Higashi, Shibuya-ku, Tokyo 150-0011, Japan. ${ }^{3}$ Laboratory of Pharmaceutical Engineering, Gifu Pharmaceutical University, 1-25-4 Daigaku-nishi, Gifu 501-1196, Japan. ${ }^{4}$ United Graduate School of Drug Discovery and Medical Information Sciences, Gifu University, 1-1 Yanagido, Gifu 501-1194, Japan. ${ }^{5}$ Present address: Clinical Research, Innovation and Education Center, Tohoku University Hospital, 1-1 Seiryo-machi, Aoba Ward, Sendai, Miyagi 980-8574, Japan.

Received: 15 September 2015 Accepted: 11 December 2015

Published online: 22 December 2015

\section{References}

1. Ruggiero LS. Guidelines for the diagnosis of bisphosphonate-related osteonecrosis of the jaw (BRONJ). Clin Cases Miner Bone Metab. 2007;4:37-42.

2. Ruggiero LS, Dodson TB, Assael LA, Landesberg R, Marx RE, Mehrotra B. American Association of Oral and Maxillofacial Surgeons Position Paper on Bisphosphonate-Related Osteonecrosis of Jaw - 2009 Update. Aust Endod J. 2009;35:119-30.

3. Ruggiero SL, Dodson TB, Fantasia J, Goodday R, Aghaloo T, Mehrotra B, et al. American Association of Oral and Maxillofacial Surgeons. American Association of Oral and Maxillofacial Surgeons position paper on medication-related osteonecrosis of the jaw -2014 update. J Oral Maxillofac Surg. 2014;72:1938-56.

4. Mariotti A. Bisphosphonates and osteonecrosis of the jaws. J Dent Educ. 2008;72:919-29.

5. Umetsu R, Nishibata $Y$, Abe J, Suzuki $Y$, Hara $H$, Nagasawa $H$, et al. Evaluation of the association between the use of oral anti-hyperglycemic agents and hypoglycemia in Japan by data mining of the Japanese Adverse Drug Event Report (JADER) database. Yakugaku Zasshi. 2014;134:299-304.

6. Cornelius VR, Sauzet O, Evans SJW. A signal detection method to detect adverse drug reactions using a parametric time-to-event model in simulated cohort data. Drug Saf. 2012;35:599-610.

7. Yamada M, Handa J. Comparison of the onset time profile among the interferon formulations in Adverse drug reaction of suicide- or diabetes related. Jpn J Pharmacoepidemiol. 2014;19:23-30.

8. Sauzet O, Carvajal A, Escudero A, Molokhia M, Cornelius VR. Illustration of the weibull shape parameter signal detection tool using electronic healthcare record data. Drug Saf. 2013;36:995-1006.

9. The International Conference on Harmonisation of Technical Requirements for Registration of Pharmaceuticals for Human Use $(\mathrm{ICH})$. Medical Dictionary for Regulatory Activities. http://www.meddra.org/. Accessed 19 Aug 2015.

10. Van Puijenbroek EP, Bate A, Leufkens HG, Lindquist M, Orre R, Egberts AC. A comparison of measures of disproportionality for signal detection in spontaneous reporting systems for adverse drug reactions. Pharmacoepidemiol Drug Saf. 2002;11:3-10.

11. Yoneda $T$, Hagino $H$, Sugimoto $T$, Ohta H, Takahashi S, Soen S, et al. Bisphosphonate-related osteonecrosis of the jaw: position paper from the Allied Task Force Committee of Japanese Society for Bone and Mineral Research, Japan Osteoporosis Society, Japanese Society of Periodontology, Japanese Society for Oral and Maxillofacial Radiology, and Japanese Society of Oral and Maxillofacial Surgeons. J Bone Miner Metab. 2010;28:365-83.

12. Kavanagh KL, Guo K, Dunford JE, Wu X, Knapp S, Ebetino FH, et al. The molecular mechanism of nitrogen-containing bisphosphonates as antiosteoporosis drugs. Proc Natl Acad Sci U S A. 2006;103:7829-34.

13. Dalle Carbonare L, Zanatta M, Gasparetto A, Valenti MT. Safety and tolerability of zoledronic acid and other bisphosphonates in osteoporosis management. Drug Healthc Patient Saf. 2010;2:121-37.

14. Lo JC, O'Ryan FS, Gordon NP, Yang J, Hui RL, Martin D, et al. Predicting Risk of Osteonecrosis of the Jaw with Oral Bisphosphonate Exposure (PROBE) Investigators. Prevalence of osteonecrosis of the jaw in patients with oral bisphosphonate exposure. J Oral Maxillofac Surg. 2010;68:243-53.

15. United States Food and Drug Administration. Background document for meeting of advisory committee for reproductive health drugs and drug safety and risk management advisory committee. September 9, 2011.
http://www.fda.gov/downloads/AdvisoryCommittees/CommitteesMeeting Materials/drugs/DrugSafetyandRiskManagementAdvisoryCommittee/ UCM270958.pdf Accessed 15 Sep 2015

16. Urade M, Tanaka N, Furusawa K, Shimada J, Shibata T, Kirita T, et al. Nationwide survey for bisphosphonate-related osteonecrosis of the jaws in Japan. J Oral Maxillofac Surg. 2011;69:e364-71.

17. Saad F, Brown JE, Van Poznak C, Ibrahim T, Stemmer SM, Stopeck AT, et al. Incidence, risk factors, and outcomes of osteonecrosis of the jaw: integrated analysis from three blinded active-controlled phase III trials in cancer patients with bone metastases. Ann Oncol. 2012;23:1341-7.

18. Ruza I, Mirfakhraee S, Orwoll E, Gruntmanis U. Clinical experience with intravenous zoledronic acid in the treatment of male osteoporosis: evidence and opinions. Ther Adv Musculoskelet Dis. 2013;5:182-98.

19. Suzuki $Y$, Suzuki $H$, Umetsu R, Uranishi $H$, Abe J, Nishibata $Y$, et al. Analysis of the Interaction between clopidogrel, aspirin, and proton pump inhibitors using the FDA Adverse Event Reporting System Database. Biol Pharm Bull. 2015;38:680-6.

20. Kato Y, Umetsu R, Abe J, Ueda N, Nakayama Y, Kinosada Y, et al. Hyperglycemic adverse events following antipsychotic drug administration in spontaneous adverse event reports. J Pharm Health Care Sci. 2015;1:15.

\section{Submit your next manuscript to BioMed Central and we will help you at every step:}

- We accept pre-submission inquiries

- Our selector tool helps you to find the most relevant journal

- We provide round the clock customer support

- Convenient online submission

- Thorough peer review

- Inclusion in PubMed and all major indexing services

- Maximum visibility for your research

Submit your manuscript at www.biomedcentral.com/submit
) Biomed Central 